Оценка фенотипа интерфазных ядер лимфоцитов методом количественного фазового имиджинга (QPI) у пациенток с эндометриоидными кистами яичников

\author{
Гаспарян С.А. ${ }^{1}$ • Попова О.С. ${ }^{1}$ Василенко И.А. ${ }^{2}$ ' Хрипунова А.А. ${ }^{1}$ - Метелин В.Б. ${ }^{2}$
}

Актуальность. Эндометриоз яичников - прогрессирующее заболевание, распространенность и тяжесть которого неуклонно возрастают. В связи с этим представляются актуальными вопросы разработки надежных неинвазивных скрининговых методов лабораторной диагностики заболевания на этапе раннего амбулаторного обследования. Цель оценка возможностей метода количественного фазового имиджинга для ранней диагностики эндометриоидных кист яичников и рецидивов заболевания в послеоперационном периоде. Материал и методы. Проанализированы 1578 ядер лимфоцитов периферической крови 82 пациенток с эндометриоидными кистами яичников в возрасте от 21 до 37 лет (средний возраст 26,4 $\pm 3,6$ года), наблюдавшихся в женской консультации (г. Ессентуки). Исследования проводили в динамике: до лапароскопической цистэктомии, через 6 и 12 месяцев послеоперационного периода на фоне или без лечения препаратами с действующим веществом диеногест. Морфофункциональное состояние ядер лимфоцитов периферической крови оценивали в режиме реального времени методом количественного фазового имиджинга (QPI) с использованием модуля фазово-интерференционной микроскопии аппаратно-программного комплекса «Биони» (ООО «Весттрейд», Москва) для клинической и лабораторной диагностики, а также технологии морфоденситометрической сегментации. Результаты. При сравнительном анализе морфометрических показателей $\mathrm{CD}^{+}{ }_{-}$ клеток периферической крови соматически здоровых небеременных женщин и пациенток с эндометриоидными кистами яичников до проведения им оперативного лечения выявлено статистически значимое повышение расчетного показателя функциональной активности ядер лимфоцитов $(0,898$ против $0,783, p<0,05)$. Исследование динамики дифференциально-диагностических критериев реактивных изменений ядер лимфоцитов периферической крови пациенток с эндометриоидными кистами яичников показало: по сравнению с результатами до лечения на 6-м и 12-м месяцах послеоперационного периода величина относительной интенсивности сегментов в ядрах $(\Delta \mathrm{l})$ снижалась на 10,3 и 14,7, 10,6 и 12,9\% в группах, получавших терапию диеногестом, и без терапии диеногестом соответственно; относительное расстояние между центрами сегментов ядер $(\Delta \mathrm{L})$ имело тенденцию к увеличению на 0,6 и 0,9, 4,2 и 2,1\%; количество сегментов в ядрах увеличивалось на 18,3 и 13,4, 27,4 и 16,9\%; периметр ядер уменьшался на 13,9 и 12,6, 11,9 и 7,8\% соответственно. Частота безрецидивных случаев через 6 и 12 месяцев наблюдения в группах больных, получавших диеногест, составила $100 \%$, тогда как у пациенток, не получавших лечение диеногестом, - 97,5 и 93,5\% соответственно. Обсуждение. Интерфазный хроматин представляет собой своеобразный биосенсор, датчик ранних изменений лимфоидной клетки. Модификации его структуры и плотности упаковки не только свидетельствуют об изменении морфофункционального состояния лимфоцита, но и могут быть спроецированы на организм в целом для ранней доклинической диагностики, оценки тяжести патологического процесса и прогноза при различных кризисных состояниях. Заключение. Практическое использование QPI в клиническом мониторинге больных с эндометриоидными кистами яичников способствует оперативному получению важной информации о состоянии клеточного звена иммунитета, открывает новые возможности для оценки эффективности проводимых лечебных и реабилитационных мероприятий, а также ранней доклинической диагностики рецидива заболевания.

Ключевые слова: фенотип интерфазного ядра, ядерная архитектура, хроматин, хроматиновые территории, фазово-интерференционная микроскопия, клинический мониторинг, эндометриоидные кисты яичников

doi: 10.18786/2072-0505-2017-45-2-109-117 


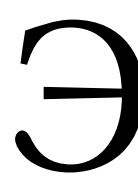
ндометриозом во всем мире страдают более 170 млн женщин. На долю эндометриоза яичников, по данным разных авторов, приходится от 17 до 44\% случаев, из которых около $30 \%$ представлены пациентками с диагностированным бесплодием. Эндометриоидные кисты яичников плохо поддаются медикаментозной терапии, и поэтому в комплексе лечебных мероприятий ведущая роль принадлежит хирургическим вмешательствам. Однако, несмотря на допустимую радикальность оперативного лечения, рецидив эндометриоза в среднем составляет $4,6,9,6,15,2,19,3$ и $17,8 \%$ за 1 , 2, 3, 4 и 5 лет после оперативного вмешательства соответственно $[1,2]$.

Этиопатогенез заболевания - достаточно сложный и многофакторный процесс, различные составляющие которого нашли отражение в многочисленных теориях, объясняющих причины инициации и распространения эндометриоидных очагов. При этом следует отметить, что практически в каждой теории, предложенной современными авторами, отмечается в той или иной мере наличие дисфункции иммунной системы. Данный факт свидетельствует о необходимости учитывать иммунные факторы, участвующие в патогенезе этого многогранного хронического заболевания, изучать патофизиологию эндометриоза, выявлять новые терапевтические мишени для достижения эффективного лечения [3-5].

Высокая заболеваемость, сложности раннего выявления и рецидивирующий характер течения патологического процесса диктуют необходимость поиска новых способов диагностики и применения современных неинвазивных технологий. В качестве одного из решений этой проблемы видится совершенствование методов мониторинга иммунного статуса пациента. Многие исследователи единодушны во мнении, что мониторирование морфофункционального состояния иммунокомпетентных клеток может оказаться крайне важным для прогнозирования состояния больного, построения индивидуальных лечебных и реабилитационных программ, сравнения эффективности различных видов терапии, своевременного выявления осложнений и побочных эффектов лечения эндометриоза [6-8].

Сегодня популярным направлением в исследовании клеток и субклеточных структур считается количественный фазовый имиджинг (quantitative phase imaging - QPI). Благодаря ценным преимуществам методы QPI можно активно использовать в медико-биологических исследованиях. Они также обеспечивают возможность
Гаспарян Сусанна Арташесовна - д-р мед. наук, профессор, профессор кафедры акушерства и гинекологии факультета дополнительного последипломного образования ${ }^{1}$

Попова Ольга Сантроевна - аспирант кафедры акушерства и гинекологии факультета дополнительного последипломного образования'

Василенко Ирина

Анатольевна - д-р мед. наук, профессор, декан факультета математики, математической биологии и биоинформатики $\triangle$ 117997, г. Москва, ул. Садовническая, 33/1, Российская Федерация. Тел.: +7 (495) 9515497. E-mail:vasilenko0604@ gmail.com

Хрипунова Алеся Александровна - канд. мед. наук, доцент кафедры общественного здоровья, организации здравоохранения и медицинской информатики'

\section{Метелин Владислав} Борисович - канд. биол. наук, доцент кафедры математической биологии,

биоинформатики и биотехнологий ${ }^{2}$

\section{'ФГБОУ ВО}

«Ставропольский

государственный медицинский университет»

Минздрава России;

355017, г. Ставрополь, ул. Мира, 310

Российская Федерация

${ }^{2}$ ФГБОУ ВО «Российский государствен-

ный университет им. А.Н. Косыгина (Технологии. Дизайн. Искусство)»; 117997, г. Москва ул. Садовническая, 33/1 Российская Федерация качественной и количественной оценки функциональной морфологии живых цитообъектов. К таким преимуществам относятся возможность изучения состояния клетки без инвазивного вмешательства в условиях, наиболее приближенных к естественным; высокая скорость регистрации данных, позволяющая отслеживать динамику внутриклеточных процессов; отсутствие сложной пробоподготовки образцов, включающей фиксацию и окрашивание, и др.

В последние годы несколькими исследовательскими группами в разных странах разработаны образцы интерференционных микроскопов, которые активно применяются в биологических и медицинских исследованиях [9-12]. Эти приборы имеют практически единую платформу, но различаются техническими решениями и алгоритмами определения фазы и анализа изображений. Новые возможности, ассоциированные с развитием современных компьютерных технологий, ведут к решению целого ряда медико-биологических проблем. В частности, разработан метод определения функционального состояния клеток на основе фазово-интерференционных характеристик их ядерных структур, включая области ядрышкового организатора, которые отражают метаболическую и пролиферативную активность клеток, а также выступают маркером их злокачественной трансформации $[11,12]$.

В связи с этим мы сосредоточили наше внимание на возможности практического использования QPI в клиническом мониторинге больных с эндометриоидными кистами яичников и выявлении дифференциально-диагностических цитологических критериев реактивных изменений ядерных структур иммунокомпетентных клеток.

\section{Материал и методы}

Проанализированы 1578 ядер лимфоцитов периферической крови больных с эндометриоидными кистами яичников в возрасте от 21 до 37 лет (средний возраст $26,4 \pm 3,6$ года), наблюдавшихся в женской консультации (г. Ессентуки). Исследования проводили в динамике - до оперативного лечения, через 6 и 12 месяцев после операционного лечения: 1-ю группу составили 82 пациентки с эндометриоидными кистами яичников, обследованные до лапароскопической цистэктомии; 2-ю и 4-ю группы - 42 пациентки, обследованные через 6 и 12 месяцев после операции на фоне лечения диеногестом в дозе 2 мг в течение 12 месяцев; 3-ю и 5-ю группы - 40 больных, обследованных через 6 и 12 месяцев после операции, не принимавших диеногест. Все пациентки 
были сопоставимы по возрасту, длительности и тяжести заболевания.

В группу контроля были включены 30 небеременных женщин фертильного возраста, не имевшие на момент обследования признаков обострения гинекологической и хронической соматической патологии, обратившиеся в консультацию по вопросам контрацепции.

Цельную венозную кровь забирали из кубитальной вены в объеме 5 мл в пластиковую пробирку с добавлением 25 ЕД гепарина на 1 мл для предотвращения свертывания крови. Взвесь мононуклеаров получали стандартным методом на градиенте плотности Ficoll-Paque $\left(\mathrm{p}=1,077\right.$ г $\left./ \mathrm{cm}^{3}\right)$. Выделение лимфоцитов из фракции мононуклеарных клеток осуществляли с помощью магнитного сепаратора MidiMACS по методике производителя (Miltenyi Biotech, Германия). Чистота выделения $\mathrm{CD}^{+}$-клеток во всех случаях составляла более $95 \%$.

Морфофункциональное состояние ядер лимфоцитов периферической крови оценивали в режиме реального времени методом количественного фазового имиджинга с использованием модуля фазово-интерференционной микроскопии аппаратно-программного комплекса «Биони» (ООО «Весттрейд», Москва) для клинической и лабораторной диагностики.

В основе принципа действия модуля, содержащего идентичные объективы в сигнальном и реперном плечах, лежит сравнение волнового фронта, прошедшего через объект, с опорным, отраженным от высококачественного зеркала. После дискретизации полученного сигнала производится запись распределения фаз в виде цифровой матрицы. Результат обратного преобразования цифрового массива в видимое изображение и восстановление фазового портрета объекта отображается на экране монитора компьютера. Пакет стандартных программ аппаратно-программного комплекса позволяет получать 2D- и 3D-визуализацию клетки и ее фрагментов, производить редактирование файлов, инверсию, вычитание кадров, картирование флуктуаций и другие операции.

Для проведения исследований использовали штатный 30-кратный микрообъектив с числовой апертурой 0,65. Увеличение в канале регистрации составляло 500 раз. Количественный анализ данных производили отдельно с помощью программных средств, разработанных в среде MATLAB. Интерферограммы обрабатывали и сохраняли фазовые изображения клеток. Для каждой клеточной популяции оценивали морфоденситометрические параметры: средние значения диаметра, периметра, высоты, площади и объема клеток. Рассчитывали показатель функциональной активности ядра (FA) как величину обратно пропорциональную фазовой высоте (PH) каждой клетки в выборке по формуле:

$$
F A=(3 \times n 3+2 \times n 2+n 1+0 \times n 0) / n,
$$

где $F A$ - функциональная активность ядра; $n 3$ - количество клеток с $\mathrm{PH} \leq 1,5$ мкм; $n 2$ c $\mathrm{PH}>1,5$, но $\leq 2$ мкм; $n 1-$ с РН $>2$, но $\leq 2,5$ мкм; $n 0-$ c PH > 2,5; $n$ - число клеток в выборке.

Для оценки ядерного полиморфизма лимфоцитов циркулирующей популяции использовали технологию денситометрической сегментации ядер на основе цифровой обработки их фазово-интерференционных изображений с помощью алгоритма «водораздел». В качестве информативных параметров анализировали:

- относительную интенсивность сегментов ядра $(\Delta \mathrm{I})$ - величину, обратную оптической плотности (отношение значения интенсивности для каждой сегментированной области к максимальному значению интенсивности);

- относительное расстояние $(\Delta \mathrm{L})$ между центрами сегментов (отношение медианы расстояний между центрами сегментов к максимальному значению расстояний);

- количество (N) сегментов по площади ядра;

- периметр (Р) ядер в пикселях (пикс).

Статистический анализ полученных данных проводили с использованием стандартного пакета прикладных программ SPSS Statistics 21.0. Стандартная обработка выборок включала подсчет значений средних арифметических величин, ошибок средних, а также величины дисперсии и среднего квадратичного отклонения. Сравнение двух связанных между собой групп по количественным признакам осуществляли непараметрическим методом с использованием теста согласованных пар Вилкоксона. Сравнение двух несвязанных между собой групп по количественным признакам осуществляли непараметрическим методом с использованием U-критерия Манна - Уитни. При сравнении двух групп с нормальным характером распределения данных использовали $\mathrm{t}$-тест для независимых группировок. Для всех видов анализа статистически значимыми считали различия при $\mathrm{p}<0,05$.

\section{Результаты}

При сравнительном анализе морфометрических показателей лимфоцитов $\left(\mathrm{CD} 3^{+}\right)$у соматически здоровых небеременных женщин и пациенток 
с эндометриоидными кистами яичников до проведения оперативного лечения установлено, что при эндометриозе яичников по сравнению с группой контроля увеличены средние по популяции следующие морфометрические параметры $\mathrm{CD}^{+}-$-клеток: диаметр, периметр, площадь и объем (таблица). Фазовая толщина ядра (фазовая высота) оказалась сниженной на 16,2\%. При этом статистически значимо повышался расчетный показатель функциональной активности ядер лимфоцитов $(0,898$ против $0,783, \mathrm{p}<0,05)$.

Полученные результаты послужили основой для исследования возможности улучшения ранней диагностики эндометриоидных кист яичников и рецидивов заболевания в послеоперационном периоде посредством использования экспресс-анализа дифференциально-диагностических критериев реактивных изменений ядерных структур лимфоцитов.

При визуализации ядра лимфоцита четко определялась его округлая или овальная форма, неоднородность внутренней структуры, связанная с наличием конгломератов гетерохроматина по периферии и в центре, наличие нескольких контрастных ядрышек (рис. 1).
Рисунок 2 иллюстрирует характер изменений анализируемых дифференциально-диагностических критериев функционального состояния ядерных структур лимфоцитов через 6 и 12 месяцев после лапароскопической цистэктомии у обследуемых пациенток в группах сравнения.

У ядер лимфоцитов больных с эндометриоидными кистами яичников до оперативного лечения были отмечены достаточно высокие значения относительной интенсивности сегментов ядра по сравнению с контрольной группой $(0,611$ против 0,504, p <0,05). Данная величина характеризует анизотропию хроматина: чем выше ее значение, тем хроматин менее плотный (более рыхлый) в данной области ядра клетки. В процессе мониторинга этого показателя на 6-м и 12-м месяце постоперационного периода у пациенток, получавших диеногест, $\Delta \mathrm{I}$ снижалась практически до нормальных значений на 10,3 и $14,7 \%$ соответственно $(\mathrm{p}<0,05)$. В группах 3 и 5 величина $\Delta \mathrm{I}$ также снижалась, но в меньшей степени, - на 10,6 и 12,9\% соответственно $(\mathrm{p}<0,05)$.

Аналогичные изменения отмечены в отношении относительного расстояния $(\Delta \mathrm{L})$ между

Морфоденситометрическая характеристика Т-лимфоцитов (CD3+-клеток) периферической крови практически здоровых женщин и больных с эндометриоидными кистами яичников до оперативного лечения

\begin{tabular}{|c|c|c|c|c|c|c|}
\hline \multirow[t]{2}{*}{ Группа } & & \multicolumn{5}{|c|}{ Морфоденситометрические параметры лимфоцитов } \\
\hline & & $\begin{array}{l}\text { диаметр } \\
\text { (Д, мкм) }\end{array}$ & $\begin{array}{l}\text { периметр } \\
\text { (P, мкм) }\end{array}$ & $\begin{array}{l}\text { высота } \\
\text { (Н, мкм) }\end{array}$ & $\begin{array}{l}\text { площадь } \\
\left(\mathrm{A}, \mathrm{MKм}^{2}\right)\end{array}$ & $\begin{array}{l}\text { объем } \\
\left(\mathrm{V}, \text { мкм }^{3}\right)\end{array}$ \\
\hline \multirow{6}{*}{$\begin{array}{l}\text { Соматически здоровые } \\
\text { женщины (контроль, } \mathrm{n}=30 \text { ) }\end{array}$} & $\max$ & 9,43 & 36,25 & 3,59 & 58,13 & 59,24 \\
\hline & $\min$ & 5,22 & 16,41 & 1,43 & 27,42 & 21,38 \\
\hline & Mean & 7,02 & 24,15 & 2,42 & 41,56 & 39,96 \\
\hline & SD & 0,54 & 5,11 & 0,44 & 9,12 & 10,15 \\
\hline & Median & 6,81 & 24,13 & 2,46 & 35,15 & 41,12 \\
\hline & $\mathrm{Fa}$ & 0,783 & & & & \\
\hline \multirow{6}{*}{$\begin{array}{l}\text { Пациентки } \\
\text { с эндометриоидными } \\
\text { кистами яичников }(n=82)\end{array}$} & $\max$ & 10,35 & 38,02 & 3,15 & 62,34 & 65,88 \\
\hline & $\min$ & 6,95 & 17,13 & 1,12 & 19,89 & 34,45 \\
\hline & Mean & 8,67 & 27,24 & 2,03 & 38,14 & 43,44 \\
\hline & SD & 0,72 & 4,96 & 0,38 & 8,15 & 12,38 \\
\hline & Median & 7,26 & 25,62 & 2,01 & 37,66 & 41,65 \\
\hline & $\mathrm{Fa}$ & $0,898^{*}$ & & & & \\
\hline
\end{tabular}

FA - функциональная активность ядра

*Статистически значимые различия между группами пациенток и показателями практически здоровых людей $(p<0,05)$ 

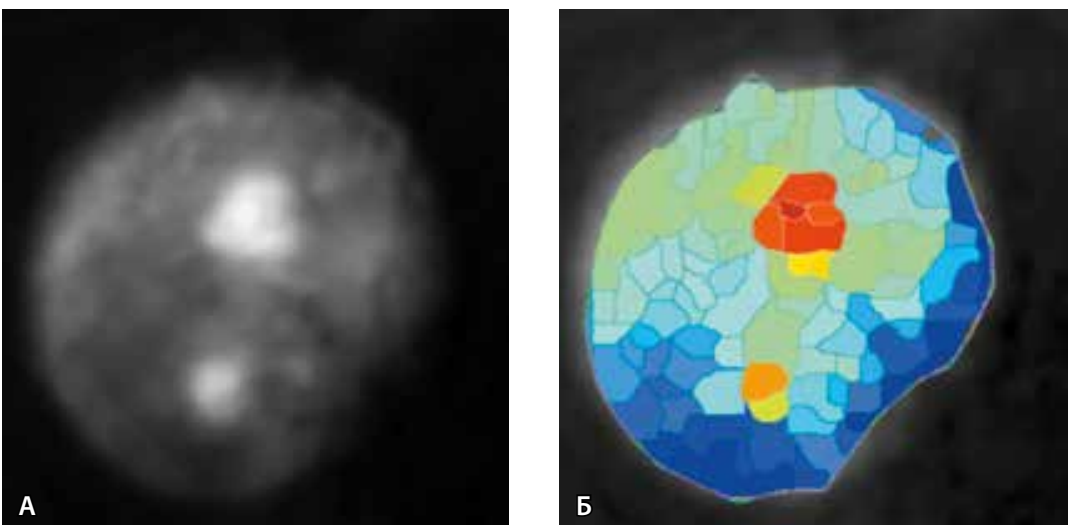

Рис. 1. Фазовый портрет ядра живого лимфоцита (А) и характер распределения хроматина в ядре, оцененный с помощью технологии денситометрической сегментации при использовании алгоритма обработки «водораздел» (Б)

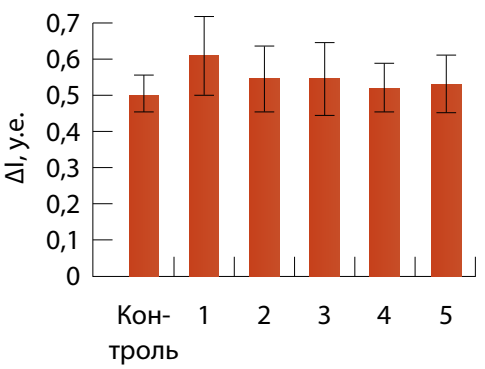

Группа пациенток

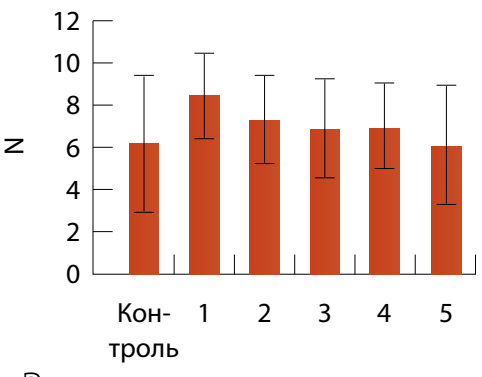

Группа пациенток

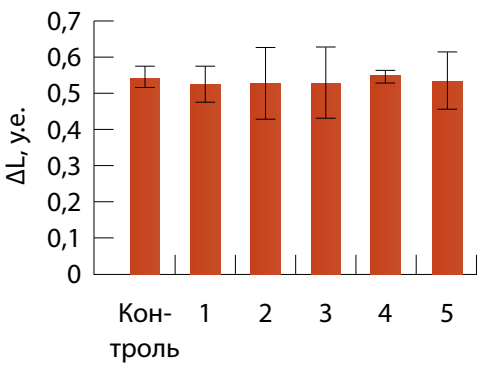

Группа пациенток

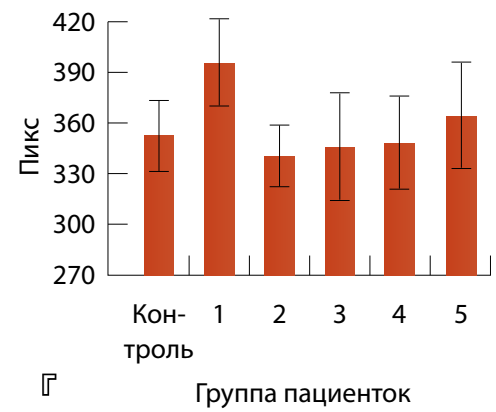

Рис. 2. Показатели реактивных изменений ядер лимфоцитов периферической крови пациенток с эндометриоидными кистами яичников до и после лечения, полученных с использованием технологии денситометрической сегментации: А - относительная интенсивность сегментов ядра ( $\triangle$ l, у.е.); Б - относительное расстояние между центрами сегментов ( $\Delta \mathrm{L}$, у.е.); $\mathbf{B}$ - количество сегментов по площади ядра (N); $\mathbf{\Gamma}$ - периметр ядер лимфоцитов (пикс). Больные с эндометриоидными кистами яичников: группа 1 - до оперативного лечения; группа 2 - через 6 месяцев после цистэктомии на фоне лечения диеногестом; группа 3 - через 6 месяцев после цистэктомии без лечения диеногестом; группа 4 - через 12 месяцев после цистэктомии на фоне лечения диеногестом; группа 5 через 12 месяцев после цистэктомии без лечения диеногестом

центрами сегментов ядер лимфоцитов, которое демонстрирует общую динамику распределения хроматина различной плотности в ядре клетки. Чем больше палитра (градация) плотности хроматина в ядре и выше уровень функциональной активности клетки, тем меньше величина данного показателя: у пациенток с эндометриоидными кистами яичников до оперативного лечения $\Delta \mathrm{L}$ составляет 0,526 против 0,545 в контрольной группе. Кроме того, это является свидетельством неоднородности распределения хроматина в ядрах таких клеток. Это связано с появлением менее крупных сегментов с большей относительной плотностью хроматина и более хаотичным их распределением по площади ядра, что характерно для клеток с высокой синтетической активностью. На фоне лечения величина показателя постепенно увеличивалась (на 0,6 и $0,9,4,2$ и $2,1 \%$ соответственно), но выявленные изменения не достигали уровня статистической значимости.

Объективным свидетельством выраженной неоднородности распределения хроматина в ядрах лимфоцитов служит подсчет количества сегментов. Так, у больных с эндометриоидными кистами яичников до оперативного лечения количество сегментов по сравнению с группой контроля было увеличенным в 1,4 раза $(8,43$ против 6,2 соответственно, $\mathrm{p}<0,05)$. На фоне лечения величина этого показателя снижалась, и в группах 2 и 3 становилась практически равнозначной (6,89 и 7,3 соответственно). Через 12 месяцев терапии у пациенток 4-й группы количество сегментов в ядрах продолжало уменьшаться и в среднем составило 6,12 $\pm 1,98$, а в 5-й группе, напротив, была выявлена тенденция к увеличению их числа до $7,01 \pm 2,81$.

Периметр ядер в группе контроля составил $353,6 \pm 21,4$ пикс, а у пациенток с эндометриоидными кистами яичников до оперативного лечения - 396,8 $\pm 26,0$ пикс $(\mathrm{p}<0,05)$. В послеоперационном периоде у пациенток в группах 2 и 4, которые получали лечение диеногестом в течение 6 и 12 месяцев, периметр ядер лимфоцитов по отношению к результатам до операции статистически значимо снижался до $341,2 \pm 18,3$ и $346,5 \pm 32,3$ пикс соответственно $(\mathrm{p}<0,05)$. У больных в группах 3 и 5 изменения были аналогичными, но менее выраженными $(349,2 \pm 28,1$ и $365,4 \pm 31,2$ пикс соответственно, $\mathrm{p}<0,05)$.

Анализ частоты рецидивов у обследованных пациенток с эндометриоидными кистами яичников после оперативного лечения показал, что через 6 и 12 месяцев число безрецидивных случаев в группах 2 и 4, получавших диеногест 2 мг, составило $100 \%$, тогда как в группах 3 и 5, не получавших лечение данным препаратом, - 97,5 и 93,5\% $(\mathrm{p}<0,05)$ соответственно. 
Таким образом, полученные результаты продемонстрировали, что прогрессирование патологического процесса у больных с эндометриоидными кистами яичников сопровождается изменением функциональной активности Т-лимфоцитарного звена иммунитета. Морфоденситометрические показатели ядер лимфоцитов могут служить критериями ранней диагностики рецидивов заболевания и эффективности проведенного лечения.

\section{Обсуждение}

Лимфоциты как объект исследования всегда привлекают пристальное внимание специалистов широким спектром функциональных возможностей, включающих контроль антигенного гомеостаза, аккумулирование, хранение и перенос информации об адаптивных и дезадаптивных процессах в системе иммунитета. Пожалуй, самым ярким и информативным элементом клеточной организации является ядро клетки. Именно поэтому детальное изучение фенотипа интерфазного ядра, к которому относят совокупность генетически детерминированных цитологических компонентов структурно-пространственной и функциональной организации цитогенетической системы (динамическую структурно-функциональную связь хроматина с элементами ядерного матрикса и внутренней ядерной оболочкой, компартментный характер организации, неслучайное расположение хромосомных территорий и др.), представляет собой важную область фундаментальных знаний [13, 14].

В этой связи интерфазный хроматин можно рассматривать в качестве своеобразного биосенсора ранних изменений функционального состояния ядросодержащей клетки. Модификации его структуры и плотности упаковки не только свидетельствуют об изменении морфофункционального состояния лимфоцита, но и могут быть спроецированы на организм в целом для ранней доклинической диагностики, оценки тяжести патологического процесса и прогноза при различных кризисных состояниях.

Количество хроматина в соматической клетке со стандартным (диплоидным) набором хромосом постоянно и не зависит от большинства факторов. В то же время в процессе активации клетки структурная упорядоченность хроматина претерпевает разнообразные конформационные превращения, в результате которых изменяются физико-химические и, соответственно, оптические (анизотропия) свойства фракций хроматина.
Известно, что коэффициент преломления всех компонентов субклеточных структур в среднем составляет 1,088 . Однако его величина может меняться в зависимости от степени конденсации хроматина: при уменьшении размера комплекса белков, ДНК и РНК снижается и коэффициент преломления. Следовательно, снижение уровня анизотропии ядра лимфоцита может интерпретироваться как показатель, свидетельствующий о переходе гетерохроматина в эухроматин, что указывает на биологическую активацию хроматина и служит предпосылкой для появления матричной активности ДНК [15].

Для описания упорядоченных структурных образований хроматина было предложено понятие «хромосомные территории», которые представляют собой динамичные структурные единицы, расположенные в трехмерном пространстве ядра и характеризующие упорядоченность процессов репликации и транскрипции хроматина. Соотношение, взаимное расположение хромосомных территорий и их позиционирование относительно друг друга и центра ядра клетки могут иметь важное диагностическое и прогностическое значение как для оценки функционального состояния клетки, так и для ранней диагностики целого ряда патологических состояний $[16,17]$.

В свою очередь, изучение организации территорий интерфазного хроматина в диапазоне масштабов от молекулярного уровня до целого ядра требует разработки соответствующих новых экспериментальных подходов. Одним из таких достаточно эффективных подходов может оказаться метод QPI $[18,19]$.

Использование уникальных возможностей QPI для неинвазивного исследования живых функционирующих клеток позволило нам получить визуализации ядерных и субъядерных структур с объективной оценкой их количественных и качественных признаков. При этом особое значение приобретает показатель фазовой толщины (или фазовой высоты) мононуклеарной клетки, который отражает особенность упаковки хроматина в ядре и, соответственно, активности процессов белкового синтеза. Таким образом, данная величина позволяет косвенно оценить активность ядросодержащей клетки и может считаться высокочувствительным и объективным критерием оценки нарушений иммунного гомеостаза [20, 21].

Нами зарегистрирован и количественно оценен процесс декомпактизации ядра с помощью используемой технологии морфоденситометрической сегментации. Существенная разница 
в величине показателей интерфазных ядер лимфоцитов (относительной интенсивности сегментов ядра $(\Delta \mathrm{I})$, относительного расстояния $(\Delta \mathrm{L})$ между центрами сегментов, количества $(\mathrm{N})$ сегментов и периметра (Р) ядер в условиях нормы и патологии (больные с эндометриоидными кистами яичников)) наглядно отражена в представленных гистограммах.

Кроме того, результаты ретроспективной оценки денситометрических параметров ядер лимфоцитов и исходов заболевания у обследованных пациенток через 6 и 12 месяцев после оперативного лечения и курса терапии продемонстрировали возможность их практического использования в качестве критериев эффективности проводимого лечения и прогнозирования рецидива эндометриоза.

Проблемы диагностики и лечения эндометриоидных кист яичников, встающие перед практикующим врачом, связаны в первую очередь с отсутствием высокочувствительных неинвазивных диагностических маркеров, позволяющих оценить характер вовлечения в патологический процесс окружающих тканей и органов при персистировании заболевания [22]. Важным аспектом профилактики рецидивов становится выбор наиболее эффективной тактики послеоперационной терапии и своевременной оценки ее эффективности и адекватности. В целом ряде стран специалисты рекомендуют в качестве монотерапии для предотвращения рецидивирования эндометриоидных кист яичников препараты на основе диеногеста - синтетического прогестина с выраженным прогестагенным и умеренным антигонадотропным эффектами без андрогенной, глюкокортикоидной и минералокортикоидной активности [2325]. Представленные нами данные убедительно подтверждают, что диеногест - высокоэффективное средство лечения эндометриоза, способствует снижению рецидивов заболевания, а морфоденситометрические показатели ядер лимфоцитов могут служить критериями эффективности терапии больных с эндометриоидными кистами яичников.

Получение важной количественной информации о состоянии клеточных объектов с применением технически доступных и малозатратных методов QPI открывает новые возможности практического использования ядер живых функционирующих клеток как перспективных биосенсоров для диагностических целей. Результаты исследования могут в будущем способствовать индивидуализации тактики ведения больных с эндометриоидными кистами яичников в послеоперационном периоде.

\section{Заключение}

Интерфазный хроматин - высокочувствительный биосенсор функциональной активности клеток. Практическое использование QPI в клиническом мониторинге больных с эндометриоидными кистами яичников способствует оперативному получению важной информации о состоянии клеточного звена иммунитета, открывает новые возможности для оценки эффективности проводимых лечебных и реабилитационных мероприятий и ранней доклинической диагностики рецидива заболевания. Важным аспектом дальнейшего развития данного направления представляется создание библиотеки фазовых образов ядер различных субпопуляций лимфоидных клеток в условиях нормы и патологии, а также совершенствование технологии цифровой обработки фазовых изображений биологических микрообъектов. (е)

\section{Литература}

1.Адамян ЛВ, Азнаурова ЯБ. Молекулярные аспекты патогенеза эндометриоза. Проблемы репродукции. 2015;21(2):66-77. doi: 10.17116/repro201521266-77.

2. Дубинская ЕД, Дутов АА, Лаптева НВ, Бабичева ИА, Колесникова СН. Эндометриоидные кисты яичников и фертильность: дискуссионные аспекты. Вопросы гинекологии, акушерства и перинатологии. 2015;14(5): 27-35.

3. Jerman LF, Hey-Cunningham AJ. The role of the lymphatic system in endometriosis: a comprehensive review of the literature. Biol Reprod. 2015;92(3):64. doi: 10.1095/biolreprod.114.124313.
4. Fazleabas AT, Braundmeier A, Parkin K. Endometriosis-induced changes in regulatory $\mathrm{T}$ cells - insights towards developing permanent contraception. Contraception. 2015;92(2):116-9. doi: 10.1016/j.contraception.2015.06.006.

5. Giuliani E, Parkin KL, Lessey BA, Young SL, Fazleabas AT. Characterization of uterine NK cells in women with infertility or recurrent pregnancy loss and associated endometriosis. Am J Reprod Immunol. 2014;72(3):262-9. doi: 10.1111/ aji.12259.

6. Berbic $\mathrm{M}, \mathrm{Ng} \mathrm{CH}$, Black $\mathrm{K}$, Markham R, Russell $P$, Basten A, Fraser IS, Hey-Cunningham AJ. A novel pilot study of endometrial stromal cells and immune cell populations in sentinel uterine-draining lymph nodes during the menstrual cycle and in endometriosis. Reprod Sci. 2013;20(11):1339-48. doi: 10.1177/1933719113485298.

7.Лысенко МА, Метелин ВБ, Баранова НВ. Опыт применения инновационных клеточных технологий в диагностике эндометриоидных кист яичников. Медицинский вестник Северного Кавказа. 2012;(2):33-6.

8. Сахаутдинова ИВ, Мустафина ГТ, Хабибуллина РН, Яркина ЕИ. Современные методы диагностики и лечения эндометриоза яичников. Медицинский вестник Башкортостана. 2015;10(1):113-7. 
9. Ceballos S, Kandel M, Sridharan S, Majeed H, Monroy F, Popescu G. Active intracellular transport in metastatic cells studied by spatial light interference microscopy. J Biomed Opt. 2015;20(11):111209. doi: 10.1117/1. JBO.20.11.111209.

10. Nguyen TH, Majeed H, Popescu G. Plane-wave decomposition of spatially random fields. Opt Lett. 2015;40(7):1394-7. doi: 10.1364/ OL.40.001394.

11. Levin GG, Vishnyakov GN, Minaev VL, Latushko MI, Pickalov VV, Demyanenko AV. Shearing interference microscopy for tomography of living cells. Proc. SPIE. 2015;9536:95360G.

12. Tychinsky V, Kretushev AV, Klemyashov IV, Zverzhkhovskiy VD, Vyshenskaya TV, Shtil AA. Quantitative phase imaging of living cells: application of the phase volume and area functions to the analysis of "nucleolar stress". J Biomed Opt. 2013;18(11):111413. doi: 10.1117/1.JBO.18.11.111413.

13. Rapkin LM, Anchel DR, Li R, Bazett-Jones DP. A view of the chromatin landscape. Micron. 2012;43(2-3):150-8. doi: 10.1016/j.micron.2011.11.007.

14. Rodriguez A, Bjerling P. The links between chromatin spatial organization and biological

\section{References}

1. Adamyan LV, Aznaurova YaB. Molecular aspects of endometriosis. Problemy reproduktsii. 2015;21(2):66-77. Russian. doi: 10.17116/ repro201521266-77.

2. Dubinskaya ED, Dutov AA, Lapteva NV, Babicheva IA, Kolesnikova SN. Endometrioid ovarian cysts and fertility: debatable aspects. Gynecology, Obstetrics and Perinatology. 2015;14(5):27-35. Russian.

3. Jerman LF, Hey-Cunningham AJ. The role of the lymphatic system in endometriosis: a comprehensive review of the literature. Biol Reprod. 2015;92(3):64. doi: 10.1095/biolreprod.114.124313.

4. Fazleabas AT, Braundmeier A, Parkin K. Endometriosis-induced changes in regulatory $T$ cells insights towards developing permanent contraception. Contraception. 2015;92(2):116-9. doi: 10.1016/j.contraception.2015.06.006.

5. Giuliani E, Parkin KL, Lessey BA, Young SL, Fazleabas AT. Characterization of uterine NK cells in women with infertility or recurrent pregnancy loss and associated endometriosis. Am J Reprod Immunol. 2014;72(3):262-9. doi: 10.1111/ aji.12259.

6. Berbic $\mathrm{M}, \mathrm{Ng} \mathrm{CH}$, Black $\mathrm{K}$, Markham R, Russell $P$, Basten A, Fraser IS, Hey-Cunningham AJ. A novel pilot study of endometrial stromal cells and immune cell populations in sentinel uterine-draining lymph nodes during the menstrual cycle and in endometriosis. Reprod Sci. 2013;20(11):1339-48. doi: $10.1177 / 1933719113485298$. function. Biochem Soc Trans. 2013;41(6):16349. doi: 10.1042/BST20130213.

15. Spagnol ST, Armiger TJ, Dahl KN. Mechanobiology of chromatin and the nuclear interior. Cell Mol Bioeng. 2016;9(2):268-76. doi: 10.1007/ s12195-016-0444-9.

16. Bernardi G. Genome organization and chromosome architecture. Cold Spring Harb Symp Quant Biol. 2015;80:83-91. doi: 10.1101/ sqb.2015.80.027318.

17. Eagen KP, Hartl TA, Kornberg RD. Stable chromosome condensation revealed by chromosome conformation capture. Cell. 2015;163(4): 934-46. doi: 10.1016/j.cell.2015.10.026.

18. Mir M, Wang Z, Shen Z, Bednarz M, Bashir R, Golding I, Prasanth SG, Popescu G. Optical measurement of cycle-dependent cell growth. Proc Natl Acad Sci USA. 2011;108(32):13124-9. doi: 10.1073/pnas. 1100506108 .

19. Lakadamyali M, Cosma MP. Advanced microscopy methods for visualizing chromatin structure. FEBS Lett. 2015;589(20 Pt A):3023-30. doi: 10.1016/j.febslet.2015.04.012.

20. Вышенская ТВ, Болотова АA, Василенко ИА, Звержховский ВД, Болдырев ДМ, Кретушев АВ, Евдокимов АА. Определение цитотоксического потенциала $\mathrm{CD}^{+}{ }^{+}$T-лим-

7. Lysenko MA, Metelyn VB, Baranova NV. New cellular technologies in diagnostics of endometrioid ovarian cysts. Medical News of North Caucasus. 2012;(2):33-6. Russian.

8. Sakhautdinova IV, Mustafina GT, Khabibullina RN, Yarkina El. Current methods of endometrioma diagnosis and treatment. Meditsinskiy vestnik Bashkortostana. 2015;10(1):113-7. Russian.

9. Ceballos S, Kandel M, Sridharan S, Majeed H, Monroy F, Popescu G. Active intracellular transport in metastatic cells studied by spatial light interference microscopy. J Biomed Opt. 2015;20(11):111209. doi: 10.1117/1. JBO.20.11.111209.

10. Nguyen TH, Majeed H, Popescu G. Plane-wave decomposition of spatially random fields. Opt Lett. 2015;40(7):1394-7. doi: 10.1364/ OL.40.001394.

11. Levin GG, Vishnyakov GN, Minaev VL, Latushko MI, Pickalov VV, Demyanenko AV. Shearing interference microscopy for tomography of living cells. Proc. SPIE. 2015;9536:95360G.

12. Tychinsky V, Kretushev AV, Klemyashov IV, Zverzhkhovskiy VD, Vyshenskaya TV, Shtil AA. Quantitative phase imaging of living cells: application of the phase volume and area functions to the analysis of "nucleolar stress". J Biomed Opt. 2013;18(11):111413. doi: 10.1117/1.JBO.18.11.111413.

13. Rapkin LM, Anchel DR, Li R, BazettJones DP. A view of the chromatin landscape. фоцитов методом когерентной фазовой микроскопии. Биофизика. 2016;61(3):523-7.

21.Vasilenko I, Metelin V, Nasyrov M, Kuznetsov A, Sukhenko E, Belyakov V. Quantitative phase imaging of cellular and subcellular structures for non-invasive screening diagnostics of socially significant diseases. Proc. SPIE. 2015;9336:93362K1-4.

22. Адамян ЛВ, ред. Эндометриоз: диагностика, лечение и реабилитация. Федеральные клинические рекомендации по ведению больных. М.; 2013.65 c.

23. Ерофеева ЛВ. Применение комбинированного контрацептивного препарата, содержащего диеногест и этинилэстрадиол, при эндометриозе. Медицинский совет. 2016;(2): 14-21.

24. Ярмолинская МИ, Беженарь ВФ. Опыт применения диеногеста в комбинированном лечении генитального эндометриоза. Фарматека. 2013;(3):48-51.

25. Park SY, Kim SH, Chae HD, Kim CH, Kang BM. Efficacy and safety of dienogest in patients with endometriosis: A single-center observational study over 12 months. Clin Exp Reprod Med. 2016;43(4):215-20. doi: 10.5653/ cerm.2016.43.4.215.

Micron. 2012;43(2-3):150-8. doi: 10.1016/j.micron.2011.11.007.

14. Rodriguez $A$, Bjerling P. The links between chromatin spatial organization and biological function. Biochem Soc Trans. 2013;41(6):16349. doi: 10.1042/BST20130213.

15. Spagnol ST, Armiger TJ, Dahl KN. Mechanobiology of chromatin and the nuclear interior. Cell Mol Bioeng. 2016;9(2):268-76. doi: 10.1007/ s12195-016-0444-9.

16. Bernardi G. Genome organization and chromosome architecture. Cold Spring Harb Symp Quant Biol. 2015;80:83-91. doi: 10.1101/ sqb.2015.80.027318.

17. Eagen KP, Hartl TA, Kornberg RD. Stable chromosome condensation revealed by chromosome conformation capture. Cell. 2015;163(4): 934-46. doi: 10.1016/j.cell.2015.10.026.

18. Mir M, Wang Z, Shen Z, Bednarz M, Bashir R, Golding I, Prasanth SG, Popescu G. Optical measurement of cycle-dependent cell growth. Proc Natl Acad Sci USA. 2011;108(32):13124-9. doi: 10.1073/pnas.1100506108.

19. Lakadamyali M, Cosma MP. Advanced microscopy methods for visualizing chromatin structure. FEBS Lett. 2015;589(20 Pt A):3023-30. doi: 10.1016/j.febslet.2015.04.012.

20.Vyshenskaya TV, Bolotova AA, Zverzhhovsky VD, Boldyrev DV, Kretushev AV, Evdokimov AA, Vasilenko IA. A technique for the assessment of the cytotoxic capacity of $C D 8^{+}$ lymphocytes based on phase images. Biophysics. 2016;61(3):440-4. 
21. Vasilenko I, Metelin V, Nasyrov M, Kuznetsov A, Sukhenko E, Belyakov V. Quantitative phase imaging of cellular and subcellular structures for non-invasive screening diagnostics of socially significant diseases. Proc. SPIE. 2015;9336:93362K1-4.

22. Adamyan LV, editor. Endometriosis: diagnosis, treatment and rehabilitation. Federal clinical treatment guidelines. Moscow; 2013.65 p.
23. Yerofeyeva LV. Administration of combined contraceptive containing dienogest and ethinyl estradiol for endometriosis. Meditsinskiy sovet. 2016;(2):14-21. Russian.

24. Yarmolinskaya MI, Bezhenar VF. Experience of use of dienogest in combined treatment of endometriosis. Pharmateca. 2013;(3):48-51. Russian.
25. Park SY, Kim SH, Chae HD, Kim CH, Kang BM.

Efficacy and safety of dienogest in patients with endometriosis: A single-center observational study over 12 months. Clin Exp Reprod Med. 2016;43(4):215-20. doi: 10.5653/ cerm.2016.43.4.215.

\title{
Evaluation of the lymphocyte interphase nuclei phenotype by quantitative phase imaging (QPI) in patients with endometrial ovarian cysts
}

\author{
Gasparyan S.A. • Popova O.S. • Vasilenko I.A. ${ }^{2}$ • \\ Khripunova A.A.' • Metelin V.B. ${ }^{2}$
}

Rationale: Ovarian endometriosis is a progressive disease with growing prevalence and severity. Therefore, the development of robust non-invasive laboratory screening methods for early diagnosis on the out-patient basis seems quite relevant. Aim: To assess a potential of the quantitative phase imaging technique for early diagnosis of ovarian endometrial cysts and post-operative relapses of the disease. Materials and methods: We analyzed 1578 nuclei of the peripheral blood lymphocytes from 82 patients with ovarian endometrial cysts, aged 21 to 37 years (mean age $26.4 \pm 3.6$ years). The patients were follow-up in a gynecology out-patient clinic (the town of Yessentuki, Russia). Assessments were made longitudinally, i.e., before a laparoscopic cystectomy, at 6 and 12 months in the post-operative period with or without treatment with dienogest-containing agents. Morphological and functional status of the nuclei from the peripheral blood lymphocytes was assessed in the real-time mode by quantitative phase imaging (QPI) with the phase-interference microscopy module of the Bioni hardware and software complex (Westgrade Ltd., Moscow) for clinical and laboratory diagnostics, and the morphodensitometric segmentation technology. Results: The comparative analysis of morphometric parameters of $\mathrm{CD}^{+}$cells taken from peripheral blood of healthy non-pregnant women and patients with ovarian endometrial cysts before surgery showed a significant increase of the calculated functional activities of the lymphocyte nuclei $(0.898$ vs 0.783 , $p<0.05$ ). Assessment of changes overt time in the differential diagnostic criteria of the nuclear response in the peripheral blood lymphocytes from patients with endometrial ovarian cysts showed the following. Compared to the parameters obtained before treatment, at 6 and 12 months of the post-operative period the relative intensity of nuclear segments $(\Delta \mathrm{I})$ decreased by 10.3 and $14.7,10.6$ and $12.9 \%$ in the group treated with and without dienogest, respectively. Relative distance between the centers of the nuclear segments $(\Delta \mathrm{L})$ demonstrated a trend towards an increase by 0.6 and $0.9,4.2$ and $2.1 \%$. The numbers of nuclear segments increased by 18.3 and $13.4,27.4$ and $16.9 \%$, whereas the nuclear perimeter decreased by 13.9 and $12.6,11.9$ and $7.8 \%$, respectively. In the patients treated with dienogest, the rate of non-relapse at 6 and 12 months of the follow-up was $100 \%$, whereas in the patients without dienogest therapy, 97.5 and 93.5\%, respectively. Discussion: Interphase chromatin is a unique biosensor of the early abnormalities in a lymphoid cell. Modification of its structure and packaging density not only indicate changes of the morphofunctional status of the lymphocyte, but can be projected to the body as a whole and used for early pre-clinical diagnosis, assessment of severity of the pathological process and prediction of the outcome in various critic states. Conclusion: Practical implementation of QPI for clinical monitoring of patients with ovarian endometrial cysts makes it possible to obtain important information on the cell immunity in real time. It opens new opportunities to assess the efficacy of treatment and rehabilitation activities, as well as for early pre-clinical diagnosis of relapsing disease.

Key words: interphase nucleus phenotype, nuclear architecture, chromatin, chromatin territories, phase-interference microscopy, clinical monitoring, endometrial ovarian cysts

doi: 10.18786/2072-0505-2017-45-2-109-117
Gasparyan Susanna A. - MD, PhD, Professor, Chair of Obstetrics and Gynecology, Faculty of Additional Professional Education

Popova Ol'ga S. - Postgraduate Student, Chair of Obstetrics and Gynecology, Faculty of Additional Professional Education

Vasilenko Irina A. - MD, PhD, Professor, Dean, Faculty of Mathematics, Mathematical Biology and Bioinformatics ${ }^{2}$

$\triangle$ 33/1 Sadovnicheskaya ul., Moscow, 117997, Russian Federation. Tel.: +7 (495) 9515497. E-mail: vasilenko0604@gmail.com

Khripunova Alesya A. - MD, PhD, Associate Profes sor, Chair of Public Health, Healthcare Organization and Medical Informatics'

Metelin Vladislav B. - PhD (in Biology), Associate Professor, Chair of Mathematical Biology, Bioinformatics and Biotechnologies ${ }^{2}$
Stavropol State Medical University; 310 Mira ul., Stavropol, 355017, Russian Federation

${ }^{2}$ Russian State University named after A.N. Kosygin (Technologies. Design. Art); 33/1 Sadovnicheskaya ul., Moscow, 117997, Russian Federation 